\title{
New Procedure of High-Voltage Electrophoresis in Polyacrylamide Gel and Its Application to the Sequencing of Nucleic Acids
}

\author{
T. V. Kutateladze, ${ }^{*}$ V. D. Axelrod,${ }^{1}$ V. G. Gorbulev, S. N. Belzhelarskaya, \\ AND R. M. VARTIKYAN
}

Institute of Molecular Biology, Academy of Sciences of the USSR, Vavilova Street, 32, Moscow B-334, USSR; *Institute of Physiology, Academy of Sciences of the Georgian SSR, Gotua Street, 14, Tbilisi, USSR

\begin{abstract}
Fractionation of nucleic acids and their fragments with polyacrylamide gel has been widely applied in sequencing of nucleic acids. Although the conditions of electrophoresis for this purpose have previously been suggested, we have found that polyacrylamide gel electrophoresis at $5000 \mathrm{~V}(100 \mathrm{~V} / \mathrm{cm})$ is possible and effective. An apparatus consisting of a horizontal thermostated plate is used to remove the heat which was formed during the electrophoretic process. The techniques for loading samples on the horizontal thin gel and the procedure for high-voltage gel electrophoresis are described and illustrated by the fractionation of the spleen phosphodiesterase partial digest of tRNA $\mathrm{V}_{2 \mathrm{a}}^{\mathrm{al}}$ as well as by the RNA synthesis by RNA polymerase from $E$. coli with poly[d(A-T)] as template in the presence of "terminator," 3'-O-methyluridine $5^{\prime}$-triphosphate. This same technique was used for electrophoresis of oligonucleotides on acetylcellulose and was incorporated into a two-dimensional system which was demonstrated by fingerprinting of the guanylo-RNase digest of $\mathrm{tRNA} \mathrm{A}^{\mathrm{Trp}}$ from baker's yeast. In the third part of the article a simple technique for the electric trapping of nucleic acids or their fragments from a slab gel on a DEAE-paper sheet is presented.
\end{abstract}

It has been found (1) that electrophoresis in denaturing polyacrylamide gel can result in the separation of DNA fragments differing by one nucleotide, involving fragments with up to $80-90$ members. This finding has considerably enlarged the scope of the classical block principle used for the study of primary structure of nucleic acids. There are now several methods available for sequencing DNA (1-4) and reports on RNA sequencing ${ }^{2}(5,6)$ based on electrophoresis in polyacrylamide gel. The electrophoretic procedure in slab gel described in these works has remained practically the same as that initially suggested for the

\footnotetext{
${ }^{1}$ Present address: Institute of Cancer Research, Columbia University, College of Physicians and Surgeons, 701 West 168th Street, New York, N. Y. 10032.

${ }^{2}$ Recently the work using $Q \beta$-replicase for sequencing RNA was published (Kramer, F. R., and Mills, D. R. (1978) Proc. Nat. Acad. Sci. USA, 75, 5334-5338.
}

separation of protein and nucleic acids $(7,8)$. That is, two glass plates are usually used for gel polymerization with their edges hermetically sealed and "pockets" provided in the upper part in which to load the samples. Electrophoresis is then conducted at 600 to $1200 \mathrm{~V}$ (about $25 \mathrm{~V} / \mathrm{cm}$ ). In this work a novel electrophoretic separation procedure is proposed for nucleic acids in polyacrylamide gel with electrophoresis proceeding at voltage as high as $5000 \mathrm{~V}(100 \mathrm{~V} / \mathrm{cm})$.

\section{MATERIALS AND METHODS}

Copolymer poly[d(A-T)] was purchased from Sigma, tRNA ${ }_{1}^{\text {Val }}$ and tRNA ${ }_{2 a}^{\text {Val }}$ were isolated from baker's yeast (9), and tRNA ${ }^{\text {Trp }}$ from baker's yeast (about 70\% purity) was kindly donated by Dr. V. Sh. Scheinker.

Nucleoside 5 -triphosphates ATP, CTP, UTP, and GTP were purchased from Sigma, $\left[\alpha-{ }^{32} \mathrm{P}\right] \mathrm{ATP}, \quad 100-300 \mathrm{Ci} / \mathrm{mmol}$, and $[\gamma-$ 
${ }^{32} \mathrm{P}$ ]ATP, $20 \mathrm{Ci} / \mathrm{mmol}$, from the Radiochemical Centre, Amersham. RNA polymerase, isolated from $E$. coli B (10), was kindly provided by Dr. R. Sh. Beabealashvili. Spleen phosphodiesterase obtained from Worthington Biochemical Corporation was additionally purified by gel filtration on Sephadex G-75. Guanyloribonuclease isolated from Actinomyces aureoverticallatus Kras. et Di Shen according to Ref. (11) was kindly provided by Dr. R. J. Tatarskaya. Alkaline phosphatase from $E$. coli was supplied by Worthington Biochemical Corporation. "Terminator," 3'-O-methyluridine $5^{\prime}$-triphosphate, was synthesized as previously described (12). $\mathrm{T}_{4}$-induced polynucleotide kinase was isolated from $E$. coli $B$ (13) and was ribonuclease free: It was unable to digest $5^{\prime}-{ }^{32} \mathrm{P}$-phosphorylated tRNA ${ }_{2 a}^{\mathrm{Val}}$ under the conditions of phosphorylation.

Acetylcellulose strips (CA 2500) were obtained from Schleicher and Schuell, DEAEpaper (DE-81) and 3MM paper from Whatman. $N, N^{\prime}$-Methylenebisacrylamide, from Reanal, was purified by recrystallization from acetone. Acrylamide (Reanal) was purified as follows: A $30 \%$ solution of acrylamide $(100 \mathrm{~g})$ in $7 \mathrm{M}$ urea was mixed with activated charcoal $(1 \mathrm{~g})$ for $30 \mathrm{~min}$. The mixture was then filtered through a glass Shott filter (No. 3), N, $N^{\prime}$-methylenebisacrylamide, EDTA, and Tris-OH were added, the $\mathrm{pH}$ was adjusted to 8.3 with boric acid, and the mixture was filtered through a nitrocellulose filter (diameter, $1 \mathrm{~cm}$; pores, $0.4 \mu \mathrm{m}$ ). The resulting solution was mixed with $7 \mathrm{M}$ urea to obtain a suitable volume. To prepare gels the following type of solution was used: $20 \%$ acrylamide, $0.67 \% N, N^{\prime}$ methylenebisacrylamide, $0.05 \mathrm{M}$ Tris - borate, $0.002 \mathrm{~m}$ EDTA in $7 \mathrm{~m}$ urea, $\mathrm{pH} 8.3$ (2). Urea, $7 \mathrm{M}$, was purified by passing through a column containing two ionite layers: Dowex 50X8, 200-400 mesh $\left(\mathrm{H}^{+}\right)$, and Dowex 1X4, 200-400 mesh $\left(\mathrm{OH}^{-}\right)$. The techniques of loading samples on the horizontal thin gel and the procedure for high-voltage gel electrophoresis are described in the next section. Autoradiographs were kept overnight at $-30^{\circ} \mathrm{C}$, with $\mathrm{X}$-ray film RM-1 or RT2 ("Swema," USSR).

\section{RESULTS AND DISCUSSION}

\section{Preparation of Polyacrylamide Gel}

All experiments were carried out in gel 0.5 $\mathrm{mm}$ thick and $500 \mathrm{~mm}$ long. The width of the gel was $10-30 \mathrm{~cm}$ depending on the number of samples loaded. To the solution prepared as described above, $0.1 \mathrm{ml}$ of a $30 \%$ water solution of ammonium persulfate and $10 \mu \mathrm{l}$ $N, N, N^{\prime}, N^{\prime}$-tetramethylethylenediamine were added. The solution was mixed for 1-2 min and poured in the slot between two polished glasses $6 \mathrm{~mm}$ thick and $600 \mathrm{~mm}$ long. A rubber cord (diameter, $1 \mathrm{~mm}$ ) was inserted between the glass edges along with a Teflon tape $5 \mathrm{~mm}$ wide and $0.5 \mathrm{~mm}$ thick that limited the gap. After having been poured the gel was kept at room temperature for $8-10 \mathrm{~h}$, one of the glasses was removed, and the sites of the gel of least density were cut off. The rectangular site of gel $500 \mathrm{~mm}$ long was covered with a polyethylene terephthalate film $0.05 \mathrm{~mm}$ thick that was strongly adhesive to the gel. This property prevents deformation of the gel under pressure and air bubbles from getting beneath the gel. The gel and polyethylene terephthalate film were carefully separated from the glass and covered with a polyethylene film $0.05-0.1 \mathrm{~mm}$ thick. The gel that was between two films was transferred on an aluminium plate for electrophoresis and connected to buffer baths by wicks of four 3MM paper layers (Fig. 1). Each of the baths contained 0.75 liter of buffer $(2 \mathrm{mM}$ EDTA, $50 \mathrm{~mm}$ Tris-HCl, pH 8.3). Preelectrophoresis was carried out for $45 \mathrm{~min}$ at $5000 \mathrm{~V}$ and $20-23^{\circ} \mathrm{C}$.

The apparatus in Fig. 1 was initially designed for high-voltage electrophoresis on paper; however, we have demonstrated that an apparatus of this type can be used to advantage for high-voltage electrophoresis on 


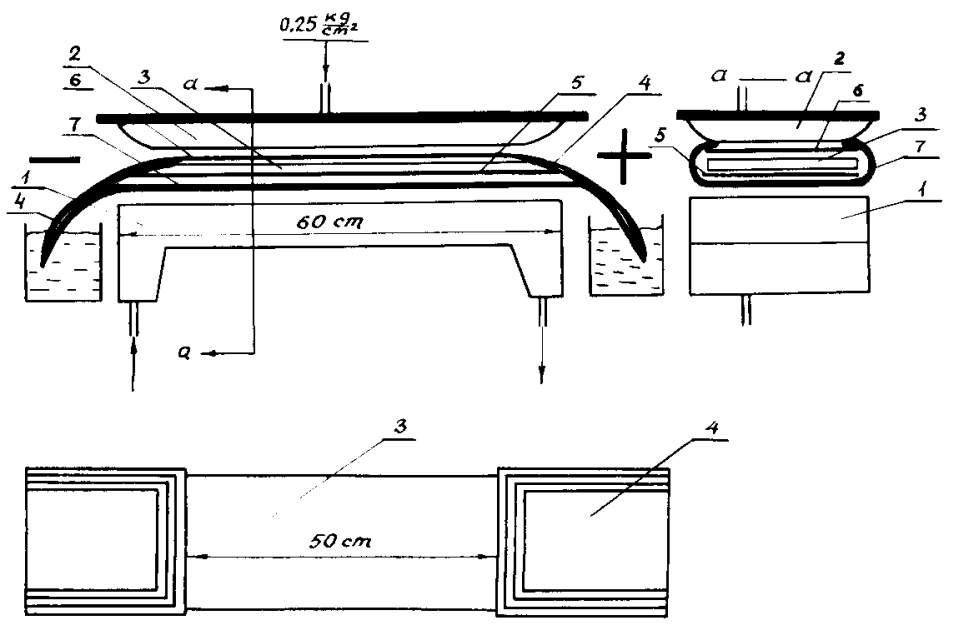

FIG. 1. Schematic drawing of the apparatus designed for electrophoresis at $5000 \mathrm{~V}$ with horizontal polyacrylamide gel. 1, thermostated aluminum plate; 2 , lid with pneumatic pillow; 3 , gel; 4 , wicks of $3 \mathrm{MM}$ paper, 5, polyethylene terephthalate film $0.05 \mathrm{~mm}$ thick; 6 , polyethylene film $0.05-0.1 \mathrm{~mm}$ thick; 7 , electroinsulating polyethylene film $0.2 \mathrm{~mm}$ thick with bent edges.

DEAE-paper (14). In the present work we show its application to electrophoresis on acetylcellulose and particularly in polyacrylamide gel.

\section{Loading of Samples on Gel}

To load samples on vertical gels "pockets" previously formed in the gel are used $(7,8)$. These, however, did not prove to be useful in our work with thin polyacrylamide horizontal gels. We attempted to use several different materials and ways to load samples on gel and one of these proved successful in giving good and reproducible results. This material was acetylcellulose. Five microliters of $7 \mathrm{M}$ urea was added to $5-8 \mu \mathrm{l}$ of the sample and the mixture was loaded on a strip of acetylcellulose $(3 \times 10 \mathrm{~mm})$, laying on a strip of polyethylene terephthalate film $2-3 \mathrm{~cm}$ wide, and allowed to dry under a lamp until moisture disappeared as evidenced by the beginning of urea crystallization. After that the polyethylene terephthalate strip and the acetylcellulose pieces were put on the gel surface for application of acetylcellulose on the gel. The gel was covered with polyethylene film, air was pumped into the pneumatic pillow of the apparatus up to $0.25 \mathrm{~kg} / \mathrm{cm}^{2}$, and the voltage $(2000 \mathrm{~V})$ was immediately switched on. After 10 min the voltage was raised to 5000 $\mathrm{V}(100 \mathrm{~V} / \mathrm{cm})$ and the temperature in the thermostat to $45^{\circ} \mathrm{C}$. RNA fragments emerged out of strips of acetylcellulose and penetrated into the gel at the very start of electrophoresis in an area that was much narrower than the starting strip (Figs. 2A and B). We loaded in this way samples on 20,15 , and $10 \%$ gels and observed a similar concentrating effect. The presence of salts (at least up to $0.1-0.2 \mathrm{M} \mathrm{KCl}$ ) in the sample did not influence this effect and subsequent electrophoresis. We tested other materials to load samples-strips of $3 \mathrm{MM}$ paper, glass paper, and polyacrylamide thin layer. But the result with acetylcellulose was the best. It is to be noted that with such loading the fragments of nucleic acids were moving not along the whole thickness of gel but in its surface layer only. This was evidenced by the fact that the radioautographs taken by applying the X-ray film to the same side of the gel to which samples were applied were much sharper than those by applying the X-ray film to the other side of gel. 
Electrophoresis at $5000 \mathrm{~V}(100 \mathrm{~V} / \mathrm{cm})$ at $45^{\circ} \mathrm{C}$ usually proceeded for $1.5 \mathrm{~h}$ but some experiments took much longer (Fig. 2).

\section{Loading of a Preparative Amount of Material on Gel}

When a relatively large amount of material is to be loaded, for purification purposes, for instance, the liquid sample of $100-150 \mu \mathrm{l}$ of $7 \mathrm{~m}$ urea, containing $0.01 \mathrm{M}$ Tris $-\mathrm{HCl}$, $0.001 \mathrm{~m}$ EDTA, $\mathrm{pH}$ 8.0, was loaded also onto a strip of acetylcellulose $(4 \times 160 \mathrm{~mm})$ lying on a strip of polyethylene terephthalate in terms of $0.5 \mathrm{OD}_{260 \mathrm{~nm}}$ for a $20-\mathrm{mm}$ length of acetylcellulose. The loaded sample on the strip was dried to absence of the
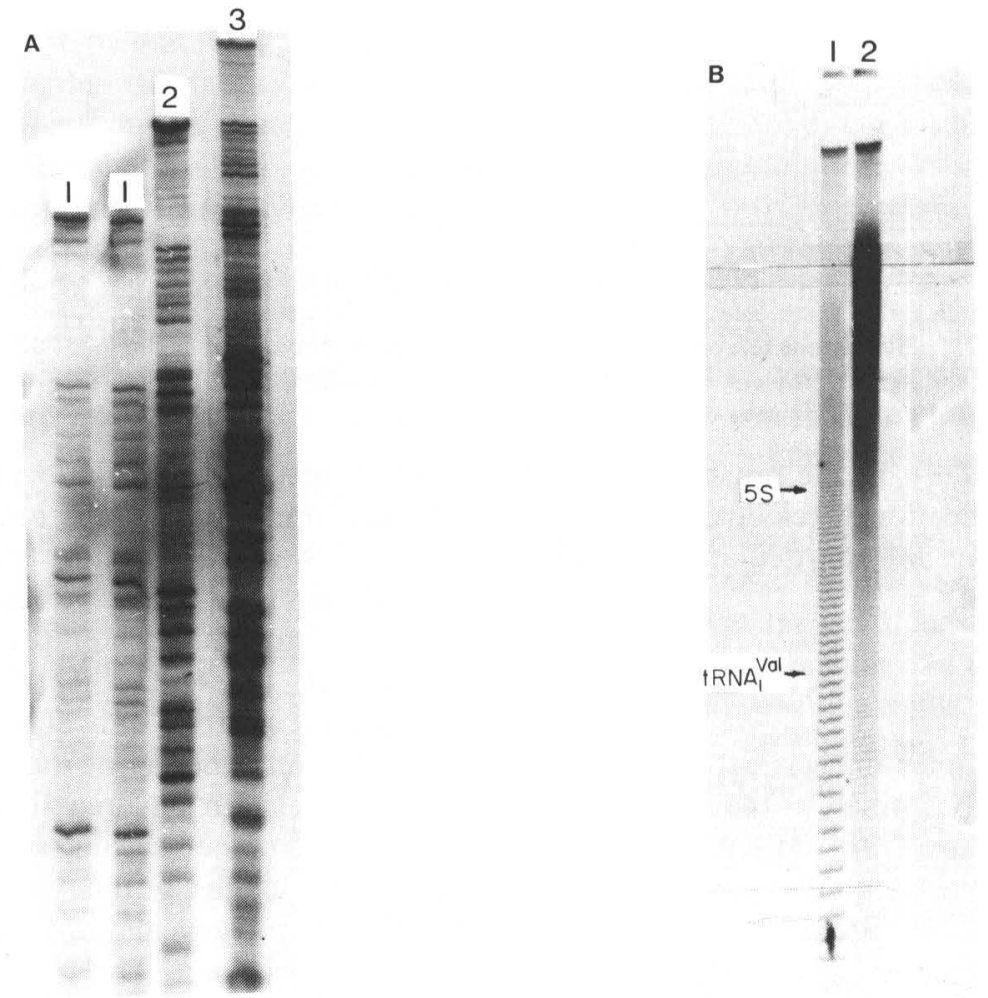

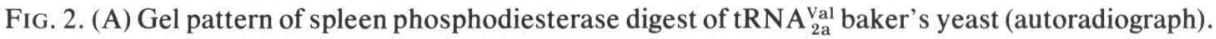
Three reaction mixtures containing $0.5 \mu \mathrm{g} \mathrm{tRNA}_{2 \mathrm{a}}^{\mathrm{Val}}$ (dephosphorylated by alkali phosphatase $E$. coli), $0.005 \mathrm{M} \mathrm{CH}_{3} \mathrm{COOH}, 0.0005 \mathrm{M}$ EDTA, $\mathrm{pH} 6.0$, and 0.01 units of spleen phosphodiesterase each were incubated at $37^{\circ} \mathrm{C}$ for $15 \mathrm{~min}, 1 \mathrm{~h}$ or $3 \mathrm{~h}$. After three samples were mixed, $6 \mu \mathrm{Ci}\left[\gamma_{-}{ }^{32} \mathrm{P}\right] \mathrm{ATP}(20 \mathrm{Ci} / \mathrm{mmol}$, $3 \mu \mathrm{l}), 3 \mu \mathrm{l}$ of buffer $\left(0.06 \mathrm{M}\right.$ Tris $-\mathrm{HCl}, 0.03 \mathrm{M} \mathrm{MgCl}_{2}, 0.045 \mathrm{M}$ 2-mercaptoethanol), and $3 \mu \mathrm{l}$ polynucleotide kinase ( 0.4 units) (13) were added, incubated $30 \mathrm{~min}$ at $37^{\circ} \mathrm{C}$, and stopped by $2 \mu 1$ of $0.5 \mathrm{M}$ EDTA. Conditions of the electrophoresis: $5000 \mathrm{~V}(100 \mathrm{~V} / \mathrm{cm}), 23^{\circ} \mathrm{C} .1,2,3$ : duration of electrophoresis for 5,3 , and $1.5 \mathrm{~h}$, respectively. (B) Analysis of RNA synthesized with poly[d(A-T)] as a template in the presence of "terminator," 3 '- $O$-methyluridine 5-triphosphate (12), by electrophoresis in $20 \%$ polyacrylamide gel. Reaction mixture $(7 \mu \mathrm{l})$ contained $1.8 \mu \mathrm{Ci}\left[\alpha^{-32} \mathrm{P}\right]$ ATP $(7 \mathrm{M})$, UTP $(20 \mu \mathrm{M})$, "terminator" $(200 \mu \mathrm{M})($ column 1) or no terminator (column 2), Tris- $\mathrm{HCl}(0.05 \mathrm{M}), \mathrm{pH} 8.0, \mathrm{KCl}(0.1 \mathrm{M})$, $\mathrm{MgCl}_{2}(0.01 \mathrm{M})$, poly[d(A-T)] $(30 \mu \mathrm{g} / \mathrm{ml}), \mathrm{ApU}(32 \mu \mathrm{M})$, and RNA polymerase $(15 \mu \mathrm{g} / \mathrm{ml})$. After poly[d(A-T)], RNA polymerase, ATP, and ApU were added the mixture was incubated $15 \mathrm{~min}$, and UTP and terminator were added. Elongation ran $30 \mathrm{~min}$ at $20^{\circ} \mathrm{C}$ and was stopped by adding $1 \mu \mathrm{l}$ of 0.5 M EDTA. Twenty micrograms of tRNA ${ }_{1}^{\text {val }}$ baker's yeast and $25 \mu \mathrm{g}$ of $5 \mathrm{~S}$ RNA rat liver were added as markers before reaction mixture was loaded on gel. Markers were discovered in the gel under uv light by loading on the gel luminescent class. Conditions of electrophoresis: $5000 \mathrm{~V}(100 \mathrm{~V} / \mathrm{cm}), 5 \mathrm{~h}, 45^{\circ} \mathrm{C}$. 
noticeable moisture and loaded on gel as described above for small samples. Such purification of tRNA $A_{1}^{\mathrm{Val}}$ baker's yeast is shown in Fig. 4.

Figure 2A gives the results of separation in $20 \%$ gel of the products of partial digestion of tRNA ${ }_{2 \mathrm{a}}^{\mathrm{Val}}$ baker's yeast by spleen exonuclease. Figure 2B demonstrates the results of electrophoresis in the same gel used for the products of RNA synthesis on the poly[d(A-T)] template both in the presence of terminator $3^{\prime}-O$-methyluridine 5 '-triphosphate and in its absence.

\section{Two-Dimensional System: Acetylcellulose- Gel}

In the section concerned with sample loading on horizontal gel we noted the concentration phenomenon observed upon loading on the gel a sample using a strip of acetylcellulose. This led us to suggest the use of two-dimensional electrophoresis first on acetylcellulose at $\mathrm{pH} 3.5$ (in terms of the composition of bases) (15) and second in gel at $\mathrm{pH} 8.3$ (in terms of the length of the oligonucleotide). Good resolution is expected a priori, there being a direct analogy with the well-known two-dimensional system: electrophoresis on acetylcellulose at $\mathrm{pH} 3.5-$ homochromatography (15). The realization of this suggestion was made possible by the availability of our procedure of horizontal electrophoresis in gel and that of sample loading. It was therefore possible to apply a strip of acetylcellulose directly to gel.

Electrophoresis in acetylcellulose was effected with the same horizontal apparatus (Fig. 1) at $20-23^{\circ} \mathrm{C}$. To this end a strip of acetylcellulose $10 \mathrm{~mm}$ wide and $500 \mathrm{~mm}$ long was immersed in $7 \mathrm{M}$ urea containing 0.5 $\mathrm{M}$ potassium citrate, $0.002 \mathrm{M}$ EDTA, $\mathrm{pH}$ 3.5 . The wet strip was placed on a polyethylene film and covered with a second polyethylene film. The strips of filter paper were placed along acetylcellulose at in-

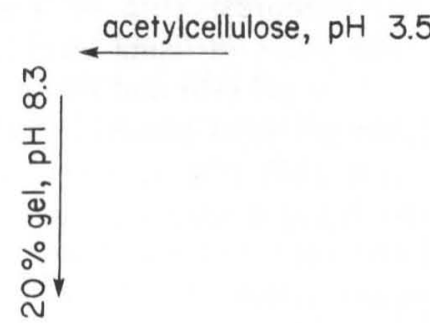

FIG. 3. Two-dimensional electrophoresis of guanylo-RNase digest of tRNA ${ }^{\mathrm{Trp}}$ (70\% purity) from baker's yeast. I, direction of electrophoresis on acetylcellulose at $\mathrm{pH} 3.5\left(5000 \mathrm{~V}, 100 \mathrm{~V} / \mathrm{cm}, 23^{\circ} \mathrm{C}, 60\right.$ $\mathrm{min})$; II, electrophoresis in $20 \%$ polyacrylamide gel at $5000 \mathrm{~V}(100 \mathrm{~V} / \mathrm{cm}), 1.5 \mathrm{~h}, 45^{\circ} \mathrm{C}$. After digestion by guanylo-RNase ${ }^{32} \mathrm{P}$ was incorporated into $5^{\prime}$ ends of the oligonucleotides with $5^{\prime}$-hydroxyl polynucleotide kinase and $\left[\gamma_{-}{ }^{32} \mathrm{P}\right] \mathrm{ATP}$, as was described in the legend to Fig. $2 \mathrm{~A}$. 


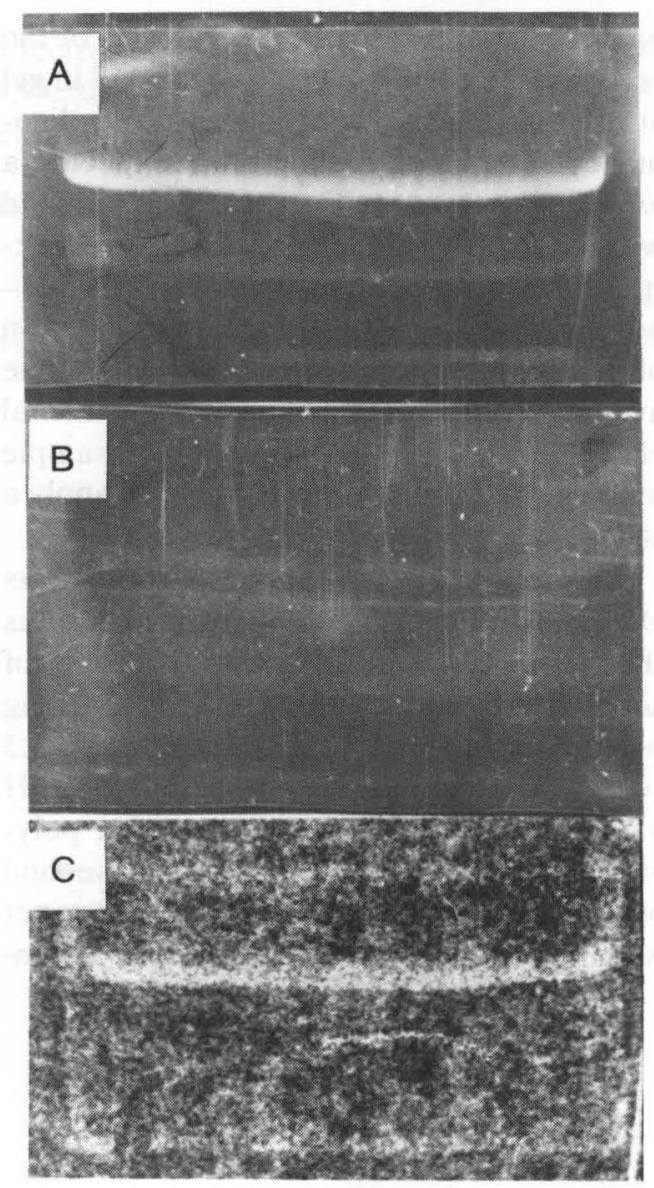

FIG. 4. Illustration of electric trapping of $t R N A_{1}^{\text {Val }}$ from $20 \%$ polyacrylamide gel on DEAE-paper. Contact photoprints under uv light. (A) $\operatorname{tRNA}_{1}^{\mathrm{Val}}(200 \mu \mathrm{g})$ in gel after its purification by electrophoresis. (B) Gel A after tRNA have run off the gel and been absorbed on DEAE-paper (C). Duration of electric trapping, $1.5 \mathrm{~h}$ at $10 \mathrm{~V}(20 \mathrm{~V} / \mathrm{mm})$.

tervals of about $3 \mathrm{~mm}$. The whole system was pressed for $5 \mathrm{~min}$ by means of a pneumatic pillow under $0.5 \mathrm{~kg} / \mathrm{cm}^{2}$. Filter paper strips were removed and $3 \mathrm{MM}$ paper wicks were wetted in buffer $(0.05 \mathrm{M}$ potassium citrate, 0.02 м EDTA, pH 3.5), squeezed with filter paper, and placed on the ends of the acetylcellulose strip, one wick on each end. Sample loading on cellulose was carried out either directly on the start of the volume of $0.5-1 \mu \mathrm{l}$ or on a separate piece of acetylcellulose $(3 \times 5 \mathrm{~mm})$ in the volume 3-4 $\mu \mathrm{l}$, dried only to remove noticeable moisture and applied to the start. Electrophoresis was carried out for $20 \mathrm{~min}$ at $500 \mathrm{~V}$ and for $60 \mathrm{~min}$ at $5000 \mathrm{~V}$, with the bromphenol blue dye migrating $18 \mathrm{~cm}$ from the start. The acetylcellulose strip was then autoradiographed at $-40^{\circ} \mathrm{C}$, and the suitable site of the strip was cut out and stuck to the gel surface. The gel and acetylcellulose were covered with polyethylene film, and air was pumped into the pneumatic pillow of the apparatus up to $0.25 \mathrm{~kg} / \mathrm{cm}^{2}$. Electrophoresis was carried out for $10 \mathrm{~min}$ at 2000 $\mathrm{V}$ and $1.5 \mathrm{~h}$ at $5000 \mathrm{~V}$ at $45^{\circ} \mathrm{C}$. The results of using the two-dimensional system are shown in Fig. 3. It will be seen that this system provides good resolution.

\section{Extraction from Gel}

The electrophoretic extraction was applied to tRNA $A_{1}^{\text {Val }}$ trapped from the slab gel after purification of $\mathrm{tRNA}_{1}^{\mathrm{Val}}$ by gel electrophoresis (Fig. 4). The literature lists some ways of using electric fields for destaining gel (16) and extracting substances from gel sites placed in tubes on DEAEpaper disks (17). Our procedure is novel in that it apparently permits all spots or bands to be extracted from the slab gel on DEAEpaper simultaneously. A simple and cheap apparatus developed for this purpose consisted of two graphite plates with slab gel placed between them, DEAE-paper, insulating polyethylene film, and several layers of $3 \mathrm{MM}$ paper acting as electrophoretic baths on the + and - sides of the system (Fig. 5). Graphite proved to be the only cheap material available for anode that did not release cations that soiled the DEAEpaper. The second graphite plate was used as cathode but also could have been made of aluminium or stainless steel. The composition of cathode and anode buffers is given in the legend to Fig. 5. Four upper layers of $3 \mathrm{MM}$ paper were impregnated with 


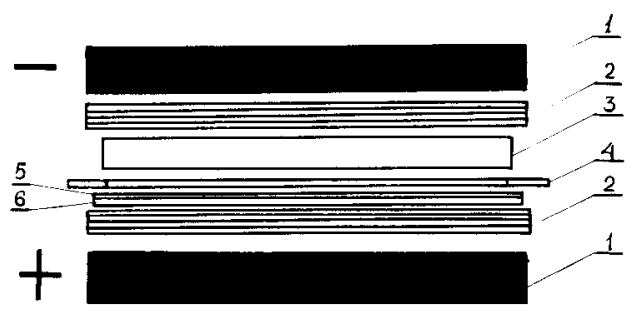

FIG. 5. Schematic drawing of the apparatus for electric trapping of nucleic acids or their fragments from slab gel on DEAE-paper. 1, graphite plates (1.5 $\times 15 \times 25 \mathrm{~cm}) ; 2$, Whatman 3 MM paper wetted with 1 mM Tris- $\mathrm{HCl}$, pH 8.3 (on the cathode), or $1 \mathrm{~mm}$ Tris- $\mathrm{HCl}, 1 \mathrm{~mm}$ EDTA, pH 8.3 (on the anode); 3, polyacrylamide gel; 4 , polyethylene film $0.05 \mathrm{~mm}$ thick with a "window; 5 , Whatman No. 1 paper; 6 , DEAEpaper.

cathode buffer and squeezed with filter paper. Four lower layers of $3 \mathrm{MM}$ paper and the DEAE-paper were impregnated with anode buffer. With a gel thickness of 0.5 $\mathrm{mm}$ there is no need to apply more than $10 \mathrm{~V}$ for $1.5 \mathrm{~h}$ to transfer molecules such as those of tRNA from gel to DEAE-paper. Figure 4 illustrates the results of tRNA $A_{1}^{\text {val }}$ electrophoretic extraction from $20 \%$ gel. Electrophoretic transfer of tRNA at $10 \mathrm{~V}$ $(20 \mathrm{~V} / \mathrm{mm})$ caused only a slight warming of the gel and the whole system. After the transfer process was over DEAE-paper was placed in a polyethylene box with a perforated bottom, washed with ethanol, water, acetone, chloroform, and acetone, and dried in air. The DEAE paper was washed very carefully, since the oligonucleotides or tRNAs were adsorbed to the surface fibers. DEAE-paper could stick to the less dense gel containing 12 or $8 \%$ acrylamide. Therefore a layer of Whatman No. 1 paper was inserted between it and the gel. The substances were extracted from dry DEAE-paper by elution with $2 \mathrm{M}$ triethylammonium bicarbonate, $\mathrm{pH} 8.3$, followed by vacuum evaporation at $45^{\circ} \mathrm{C}$ to give tRNA in a $60-70 \%$ yield.

\section{ACKNOWLEDGMENTS}

The authors thank Helena Naparyina for good assistance, Dmitry Sheinker for technical help, and Dr. F. R. Kramer for help in correction of the manuscript.

\section{REFERENCES}

1. Sanger, F., and Coulson, A. R. (1975) J. Mol. Biol. 94, 441-448.

2. Maxam, A. M., and Gilbert, W. (1977) Proc. Nat. Acad. Sci. USA 74, 560-564.

3. Sanger, F., Nicklen, S., and Coulson, A. R. (1977) Proc. Nat. Acad. Sci. USA 5463-5467.

4. Barnes, W. M. (1978) J. Mol. Biol. 119, 83-87.

5. Donis-Keller, H., Maxam, A. M., and Gilbert, W. (1977) Nucl. Acids Res. 4, 2527-2537.

6. Simoncsits, A., Brownlee, G. G., Brown, R. S., Rubin, J. R., and Guilley, H. (1977) Nature (London) 269, 833-836.

7. De Wachter, R., and Fiers, W. (1971) in Methods in Enzymology (Colowick, S. P., and Kaplan, N. O., eds.), Vol. 21, pp. 167-178, Academic Press, New York/London.

8. Akroyd, P. (1967) Anal. Biochem. 19, 399-410.

9. Kryukov, V. M., Isaenko, S. N., Axelrod, V. D., and Bayev, A. A. (1972) Mol. Biol. (USSR) 6, $860-865$.

10. Aivasashvili, V. A., Beabealashvili, R.Sh., and Florentjev, V. L. (1977) Mol. Biol. (USSR) 11, 854-863.

11. Tatarskaya, R. I., Abrossimova-Amelyanchik, N. M., Axelrod, V. D., Korenyako, A. I., Niedra, N. I., and Bayev, A. A. (1966) Biochimia (Moscow) 31, 1017-1026.

12. Axelrod, V. D., Vartikyan, R. M., Aivasashvili, V. A., and Beabealashvili, R.Sh. (1978) Nucl. Acids Res. 5, 3549.

13. Richardson, C. C. (1971) in Procedures in Nucleic Acids Research (Cantoni, G. L., and Davies, D. R., eds.), Vol. 2, pp. 815-828, Harper \& Row, New York.

14. Gorbulev, V. G., Kutateladze, T. V., Barciszewski, J., and Axelrod, V. D. (1977) Biochem. J. 163, 409-410.

15. Brownlee, G. G., Sanger, F., and Barrell, B. G. (1968) J. Mol. Biol. 34, 379-412.

16. Shortess, D. K. (1974) Anal. Biochem. 60, 329-331.

17. Adams, J. M., Jeppensen, P. G. N., Sanger, F., and Barrell, B. G. (1969) Nature (London) 223, 1009-1014. 